\title{
The National Schizophrenia Fellowship: Charity, Caregiving and Strategies of Coping, 1960-1980
}

\author{
Alice Brumby
}

\section{INTRODUCTION}

In 1970, the newly formed Schizophrenia Action Committee claimed that 'Schizophrenia is one of the greatest crippling scourges of mankind.' ${ }^{1}$ The pamphlet was a call to arms, seeking members to join and bolster this new organisation. It called for those with personal experience and first-hand knowledge of the condition to make themselves known and come together with like-minded people, to help and be helped in return. Schizophrenia is still in the 'unmentionable classes' of stigmatised illnesses, the pamphlet argued, highlighting that 'to drag the horrible problem into the full light of day and publicity was the only way of dealing with it.' ${ }^{2}$ Explaining that the community care programme and new drugs meant that more schizophrenic persons were being pushed out of closing mental hospitals and back into the homes of the often unprepared and ill-equipped, good-will of families and caregivers, the article

\footnotetext{
A. Brumby $(\square)$

York St John University, York, UK

e-mail: a.brumby@yorksj.ac.uk

(C) The Author(s) 2020

S. J. Taylor and A. Brumby (eds.), Healthy Minds

in the Twentieth Century, Mental Health in Historical Perspective, https://doi.org/10.1007/978-3-030-27275-3_9
}

189 
concluded; 'If you agree that a new voluntary society is required, will you help?'3

The path to community care and evaluating the effectiveness of community care services has been widely documented by historians over the past few decades. ${ }^{4}$ Within this history, the role of individual patients and their families has also received much attention. ${ }^{5}$ Alex Mold has identified that historically there has been 'a culture of paternalism' within the medical profession, which advocated patients taking a largely passive role in their relationship with their doctors. ${ }^{6}$ However, as Ali Haggett explains, 'during the 1960s, this situation began to change, heralded by the growth of post-war social surveys and the emergence of early patient advocacy groups, which demonstrated that patients wanted more information about health and disease. ${ }^{7}$ This emergence of early patient advocacy groups corresponds with the work of Dyck and Russell in Chapter 8 of this volume. Following on from their work however, this chapter suggests that it was not only the patients, but the families who wanted more information in the 1960s. As such, this chapter aims to recount the narrative of a collection of families who came together to form a pressure group to support each other in their quest to provide better care to their loved ones who had being diagnosed with schizophrenia.

Historically, the role of the families themselves in trying to understand their relatives' mental health condition has been well documented. ${ }^{8}$ Historians have revealed how families were instrumental in all aspects of institutional life, from committal, to corresponding with loved ones and superintendents during treatment, to reclaiming their loved ones from the grasp of the asylum when they were in a better social or financial position to cope with their illnesses. ${ }^{9}$ Nicole Baur has identified that patients' families could very often be extremely vocal in the recovery process for their loved ones suggesting that in the 1930s, 'many patients and relatives welcomed the new treatments, as they often provided the only glimpse of hope for a cure.'10 By the 1960s, this relationship between families and medical authorities remained in friction, and families complained of having to deal with the 'obfuscating fog of hospital vagueness and evasiveness. " 1972, argued that 'relatives seldom have the chance to share what little they have learnt with professional workers. Still less of course, are they in the position to make themselves heard by central policy makers and social services. They are unorganised [and] shy of publicity. ${ }^{12}$ 
Charitable bodies were not new to the mental health sector in the second half of the twentieth century. The Mental After-Care Association, established in 1879, as 'The After-Care Association for Poor and Friendless Female Convalescents on Leaving Asylums for the Insane,' was the first association to assist those recovering from mental disorder. ${ }^{13}$ Moreover, the National Association for Mental Health [N.A.M.H] had been in existence since 1946, merging from a variety of pre-existing charities: the Central Association for Mental Welfare (founded 1913), the National Council for Mental Hygiene (established 1922) and the Child Guidance Council (formed 1927). ${ }^{14}$ However, the evidence suggests that some families and caregivers felt unsupported by such a large and impersonal umbrella organisations. ${ }^{15}$ Letters identified that some family members wanted more personal support groups to aid them with their individual problems and illnesses. ${ }^{16}$ From the backdrop of these frustrations, a number of charities, pressure groups and support groups sprang up in the 1970s. The N.A.M.H itself was rebranded to become MIND in 1972, to overcome a public perception that it was becoming old-fashioned. ${ }^{17}$

Using the National Schizophrenia Fellowship (NSF) as a case study, this chapter will identify how different stakeholder groups, including families and caregivers, attempted to respond to government policies and the perceived shortfalls in state provision for mental health care in the late twentieth century. The origins of the NSF lay as a fellowship for those who knew, looked after, or cared for relatives, family members or friends suffering from schizophrenia. In his work, Peter Barham has described the early days of the NSF as an organisation which 'maintained an intransigently patronising attitude towards its constituents. ${ }^{18}$ Despite this assessment, this chapter will show that this opinion may have been created because this organisation was substantially more than just a charity for those who were suffering from schizophrenia. Instead, it was a support group, a network where the 'healthy' non-schizophrenic relative, friend or caregiver could access the support that they needed, not necessarily to care for their loved one or charge, but also to care for their own mental health needs.

This chapter will look at the beginning of the movement for a care regime and support network in the UK from the perspective of one of the very founding members of the organisation, E.A., using oral history to bring the narrative to life. Interspersed with the oral history, this 
chapter will also look at surviving documents from the NSF archives, looking at papers, council minutes and publications of the NSF itself. This chapter will show how the National Schizophrenia Fellowship helped to support relatives struggling with stigma and acted as a barrier to this stigma, thus providing strategies of coping for the 'healthy mind' of the non-schizophrenic caregiver. One of the arguments that are central to this chapter is that stigma manifested itself in a variety of ways. Many of the relatives and friends of those suffering from schizophrenia felt the stigma themselves, and certainly, their loved ones felt it keenly. ${ }^{19}$ My interviewee, E.A., although proud and fiercely independent, asked to be anonymised in this chapter. The reason that was stated for desiring such anonymity is that although her brother passed away many years ago, he never wanted E.A. to talk about his 'episodes' or his times in hospital, a request that she dutifully promised. In the interview, she states, 'And so that's my anxiety now that I might let P.A. down by telling anybody. ${ }^{20}$ To preserve her promise to her brother and therefore to preserve his anonymity, E.A. herself must remain anonymous in this chapter. Those who may be able to identify her are asked to respect her wishes and preserve her (and therefore her brother's) anonymity. ${ }^{21}$

In 2002, the National Schizophrenia Fellowship underwent a rebrand to encompass a broader diversity of mental illnesses, renaming itself 'Rethink' in the process. Although as a charity, it is still registered under the name National Schizophrenia Fellowship, 'Rethink' became known as Rethink Mental Illness in 2011, officially trading under this name. Throughout the interview, E.A. uses the term 'Rethink' to refer, anachronistically, to the National Schizophrenia Fellowship. Whilst I have preserved her use of the name 'Rethink' when quoting from her interview, I have tried to preserve the appropriate historically accurate name in the text.

\section{On Our Own, with the Medical Authorities}

Like many people with schizophrenia, P.A. was in his early twenties when his symptoms first started to manifest themselves. P.A. lived with his mother and sister, in London in the mid-1960s. His father had died in the war when P.A. was just a small boy. P.A. himself had served briefly in the army and had a good service; however, by the end of his service, his problems started to become apparent. After coming out of the army, P.A. suffered a couple of suicidal attacks. In the early 1960s, before receiving diagnosis or treatment, his psychotic symptoms really started 
to become problematic. E.A.'s narrative identifies the struggle to receive a diagnosis and the attitudes her family experienced by both the community and medical professionals at the time.

Although, as will become clear, E.A. was evidently upset about the reaction from her neighbours, relatives and lay community more generally, the interview identifies that she felt extremely supported by the medical professionals. Within the interview, she praises the 'dear old metropolitan police, ${ }^{22}$ the doctors and the mental hospital that her brother was sent to and has special praise for the community psychiatric nurses [CPNs] who cared for her brother on numerous occasions throughout his illness. Nevertheless, at the outset of her brother's illness, E.A. identifies how receiving a diagnosis by any medical professional proved challenging. E.A. recounts how at the beginning of the illness, in the early 1960s, when P.A. had just started to become 'very psychotic' every attempt to achieve a diagnosis was hindered:

But every time this GP made an appointment for P.A., P.A. said that there was nothing wrong. We told P.A. that he had to let the doctor look at him, but every time the GP came, he said there's nothing wrong, there's nothing wrong with me and that's why it went on such a long time, before he could get treatment. So we never actually managed to get him the appointment that he needed. ${ }^{23}$

P.A.'s first treatment in a mental hospital was eventually secured in 1964. His route to treatment began during one of P.A.'s psychotic attacks. After aimlessly wandering for hours one January night without a coat, P.A. was confronted by the police, and he ended up in a Magistrates' Court for hitting a policeman. ${ }^{24}$ After this, he was remanded in custody for the night and the following day:

The magistrate recommended that he go to Brixton Prison hospital for assessment by a medical person, for about four weeks [...] The prison medical officer wrote to mum and he said in his opinion he had observed that P.A. was in the early stages of paranoid schizophrenia, which if left untreated could lead to certification [...] He said that he intended to recommend to the magistrate that P.A. be sectioned for one year in hospital $[\ldots]$ So because of the police he got into the hospital- otherwise he wouldn't have. Not everybody with a mental illness goes banging on a surgery door saying will you please assess me- even now they don't! ${ }^{25}$ 
After receiving treatment in the psychiatric hospital, E.A. describes how her brother recovered very quickly in this care setting. When her mother first went to see P.A. in the hospital, she was worried he might blame her for his situation. However, E.A. narrates how her brother was actually able to reassure their mother saying-'it's okay here, they know what they are talking about. They understand. I'll be alright here. ${ }^{26}$ E.A. identifies how, 'from the time he went through those gates with the classical urns on them, he thought perhaps he could open up,' noting that 'the only person that he had ever opened up to before was me. 27

Talking of her experiences with the medical services in general, E.A. stated: 'So in a way we were lucky... the NHS people were brilliant, with us as a family and with P.A., and on the whole, we were really quite friendly with the CPNs. And on the whole, we have a lot to be thankful for. It isn't always the case today. ${ }^{28}$ Nevertheless, even with such a positive experience of mental health services, it is clear that E.A. needed more than this for reassurance and assistance for looking after her brother on a day-to-day basis. When asked what the real benefit of the National Schizophrenia Fellowship was, E.A. stated unthinkingly:

It offered more support- I should have said that. In the beginning, the first eight years before Rethink, those first eight years or so the medical people were very good, as I told you, but we were completely on our own apart from that. ${ }^{29}$

This notion of being completely alone without any support is really important, and E.A. explained how this loneliness was frequently made worse by the stigma which attached itself to the diagnosis of 'schizophrenia' in the mid-1960s.

\section{Stigma AND FeELINGS OF LONELINESS}

Before joining the Fellowship, E.A. often described a feeling of loneliness, which was inherently linked to the stigma which she and P.A. knew were attached to his condition. In periods of 'wellness', she argued that herself and her brother could easily conceal his diagnosis. She mentioned many of P.A.'s friends, stating 'So for 17 years these friends had no idea, and sometimes they'd say "oh P.A. is a law unto himself" or "P.A. is a bit eccentric" but that's all, nothing more. But I shouldn't have had to hide it. ${ }^{30}$ The halfway house of wellness and illness which could be 
experienced by the episodes of schizophrenia has clearly led E.A. to lead a life of silence, trying to keep her promise to her brother, whilst remaining interested and wanting to find the release of talking to others.

Anyway P.A. said to me, "promise me, you will not ever mention anything to do with me ever being in a mental hospital to my friends." I mean they were good friends, but he didn't know how they were going to react and he wasn't going to take the chance. And do you know, even now, I'm still keeping quiet about it. I mean I do not approve of having to keep quiet about it- do you understand? I don't approve. I support Rethink, they know I do... but a promise is a promise, even when a person is no longer here. I mean if they hear obliquely about it from some other means, then I don't worry too much, but I will never say anything about it to his friends. And so really sometimes it gets a bit awkward or something and my poor old brain, you know, I think to myself sometimes I need to put my brain into gear before I open [my mouth]. He said that he didn't want me to tell anybody and I said well they may understand or know someone else who has had a breakdown, but he said, no, he doesn't want anybody to know. I said, okay, I won't tell anybody. ${ }^{31}$

Interestingly in the interview with E.A., it is clear that the stigma and keeping quiet were some of the hardest things about looking after her brother, harder in some respects even, than managing the illness itself. In her interview, she explains 'it was quite a big thing to cope withwho knows and who doesn't- I mean it is almost like being a hunted criminal. ${ }^{32}$ By comparing her life of silence surrounding her brother's illness to being a 'hunted criminal,' E.A. clearly identifies the difficulties and shame involved in her double life. Whilst E.A. saw no reason for this stigma, it is clear that she and her family had experienced it first-hand.

You see even one or two neighbours who used to chat to mum before, when she said she met her on the street and she said oh P.A. is behaving oddly or something and when mum said "oh he's been in hospital for a mental disorder," that neighbour withdrew. And the next time that she saw mum, she walked over on the other side of the road. And this was very hurtful to mum, I mean you have enough trouble in the first place, and then that. ${ }^{33}$

Similarly, she mentioned that family was of little help to bear the weight of P.A.'s illness. In a characteristic defence of her relatives, E.A. added, 'I think my family were frightened [they] thought they might be expected 
to get involved in financial business- which they never were because I always worked and paid my way so... that we could still have a quality of life- I thought that our happiness was paramount. ${ }^{34}$ Nevertheless, her family's response was clearly hurtful to herself and her mother; 'But, you know, I think that mum would have been pleased if our relatives would have written occasionally just to say- “oh how's P.A.? I do hope he's getting on alright." But they seemed either embarrassed or I don't know what it was. ${ }^{35}$ For many years, the burden of caring responsibilities was shared between E.A. and her mother. After her mother's death however, E.A. was on her own to care for her brother for 17 years. Speaking of her feelings of isolation, E.A. argued:

When people are very psychotic, they lose their friends, a lot of them. In fact, I will say that people not only lose their friends, but there can be distance from their relatives on both sides. I don't mean that the relatives were nasty, they were both nice families and we had happy childhoods, but mental health is too much, apparently, to come to grips with and you know, even, extended family, and so we have been more or less on our own with the medical authorities, and of course Rethink and special friends who can take it. ${ }^{36}$

The response of her family and the need to hide it from certain friends clearly left a gap of loneliness in E.A.'s life, unable to talk to anyone about the more troubling symptoms of her brother's illness, including his suicide attempts and periods of hospitalisation. Clearly, this left a mark of frustration on E.A. who still worries that she might break her promise to her brother to this day. These feelings of isolation, expressed by E.A. were extremely common. An article published in Mind and Mental Health Magazine in 1972 argued that the stigma of the illness isolated families from neighbours, communities and even their own extended families stating that the 'sheer disruptive power of schizophrenia over a family is fully intelligible only to those who have been through it.' 37

\section{A Plea for Action}

E.A.'s narrative is interesting, but not unusual, and her family were clearly not the only family trying to look after loved ones who had been, or who were waiting to be, diagnosed with schizophrenia. In 1966, two years after P.A.'s diagnosis, it was estimated that 11,419 individuals had been discharged from hospital with a diagnosis of schizophrenia, 
who had not previously been in hospital before. ${ }^{38}$ Moreover, the World Health Organization's estimate was that the risk of being diagnosed with schizophrenia was one per cent of the population as a whole. ${ }^{39}$ In 1970, it was observed that over half of all of the patients in mental hospitals or psychiatric units on any given day are diagnosed as suffering from schizophrenia. At the end of 1970, the number of schizophrenic patients in hospitals totalled around 58,000. ${ }^{40}$ If anything, E.A.'s experiences, certainly those which have been recounted in the interview, were more positive than other stories appear to have been. However, the themes of isolation and loneliness prevail in other narratives too. ${ }^{41}$ On 9 May 1970, an article featured in The Times. It took the form of a letter, and although it was published anonymously, it was written by a man named John Pringle. Pringle was a retired university professor, and he was also the father of a young man who had been diagnosed with Schizophrenia in his early twenties. The letter was a plea for action, a call to know that there were others out there who engaged in the same daily battles: battles not only against the illness of schizophrenia, but against the authorities, against the system, against the stigma of the illness and against the isolation that the condition created. In the letter, it is clear to hear the anguish and anger of a man, alone in a fiercely difficult situation. In the letter, he explains:

The word "schizophrenia" is flung about today with flip facility, bobbing up in films, television scripts, literary criticism, even political articles, mostly as some sort of modish synonym for indecisiveness. But no one who has seen the acute medical condition would ever want to use it except in its correct context. ${ }^{42}$

In his second year at Oxford University, Pringle's son had developed what was referred to as 'depression of adolescence.' Having lost his scholarship through poor attendance, he was eventually expelled from the university and sent back to live with his worried, and until that point, completely ignorant parents.

A family suddenly faced with this situation has, in my experience, two problems, and it is hard to say which is worst. The first is how best to cope with this strange, new member of the household whose moods alternate impossibly between sullen lying on his bed in the dark to wild fits of aggression, with social manners regressed to an almost animal level. 
The second problem is how to penetrate the obfuscating fog of hospital vagueness and evasiveness to obtain intelligible guidance on the first set of problems. ${ }^{43}$

Pringle's letter was a heartfelt plea of a man unable to know what action to take next. In similarity to the narrative that E.A. presents, Pringle's letter identified that positive diagnosis of schizophrenia took over two years. Pringle describes this as a time where his family were unable to receive any 'practical sense out of anybody.' Practicalities were certainly an issue of constant worry and concern for Pringle, who wrote of his frustration at not being able to find any suitable answers 'on almost any specific point on which advice was desperately needed. 44 The letter observes the frustration in the lack of communication, but predominantly lack of advice available to family members or caregivers who found themselves suddenly in an impossible situation, with a moral duty to provide care, but a lack of communication from the medical authorities, upon whom they were reliant for information and support to uphold this responsibility. Again feelings of isolation were dominant in this narrative of caregiving, and similarly to the narrative put forward by E.A., Pringle's letter suggested the segregation that he felt as more people 'gave up' on his son and his son's condition.

Schizophrenics tend to leave behind them a trail of people who righteously or despairingly, feel they have "done as much as we can" and it should be somebody else's turn. I have quite a collection of sympathetic letters "hoping your son's condition will soon improve" while regretfully saying "no" to some specific request. ${ }^{45}$

By comparing the schizophrenic patient to other classes of the disabled, Pringle suggested that they and, therefore by association, the family or caregivers 'excite none of the sympathy which surrounds other classes of the disabled.' 46 In total, the letter incited more than four hundred replies from people who were touched and moved by his words, feeling themselves in similar situations. In reference to the replies that he received, Pringle stated that he 'became involved in a remarkable volume of correspondence which opened my eyes to the sense of isolation and hopelessness to which many families up and down the country [were] living. ${ }^{47}$ As a result of this correspondence, the idea was formulated to look into the option of setting up a 'small group or society, primarily of relatives and other non-medical people, specifically devoted to schizophrenia, 
with the aim of helping families to cope with the manifold problems of the condition. ${ }^{48}$ The letters clearly echoed the emotions felt by E.A. and Pringle. ${ }^{49}$

Whilst some of the letters acknowledged that parents and relatives had approached existing mental health charities such as the N.A.M.H for help, often authors felt alone and wanted something practical to be achieved. As early as 20 July 1970, Pringle wrote to Christopher Mayhew, N.A.M.H's Chair and serving Labour MP at the House of Commons to ask for his thoughts and advice about the proposed pressure group. Setting out his desires and explanation for the necessity of such a group, Pringle observed, 'I do not believe that the kind of group that I have in mind would in any way duplicate the work which the N.A.M.H is already doing, still less cut across it. ${ }^{50}$ In a competitive world of the charitable sector, gaining approval from one of the biggest 'rival' associations was an important first step. This also suggests that the merger of the original charities who amalgamated to form the N.A.M.H had failed in its ability to remain personal. ${ }^{51}$ In his private collection, Pringle meticulously kept the notes of the families who had originally contacted him, with any information that these individuals had supplied about their attempts to elicit help from local authorities or charitable bodies. Interestingly, noted under one of these families is the line, 'asked N.A.M.H if they would arrange a meeting for relatives, but they would not. ${ }^{52}$ On the 22 July 1970, Pringle wrote to another M.P. and Chairman of the Association of Psychiatric Work (APSW), Mary Lane, again asking for advice, this time referring to his endeavours at trying to get a 'self-help group started.' ${ }^{53}$ Clearly, the desire to start a self-help group came from the feelings of the lack of help available elsewhere, even from existing mental health charitable bodies.

\section{FeELings of Support}

One of the many people who saw the letter in The Times and felt strongly enough to answer was E.A. Her brother, P.A., was living at home at the time, but had been diagnosed for many years. In answer to the question, 'how did you get involved in Rethink?' E.A. answered:

Well, it was about 8 years after P.A. had to go into hospital... I saw a letter, in The Times, and it was from a Mr Pringle. It was outlining the crises going on in mental health and his experiences $[\ldots]$ When I saw this letter, 
it so resonated with often how we were feeling and how it could be also with other people that I wrote to the PO Box number which they gave us. Mr and Mrs Pringle invited me to go over there one evening, which I did and they were very nice. And we had a discussion about it and we decided that although it was difficult to get help from the authorities, it was side-lined, in our opinion, we would make an effort ourselves to form a group- a pressure group. And at first we called it the Schizophrenia Action Committee. ${ }^{54}$

Explaining the growth of the support group in its early stages, E.A. continued:

By the second meeting we decided that... it would not in fact be done in five minutes so we changed the name to the [National] Schizophrenia Fellowship, but we still had the same aims. So that is what we did- I still have my first membership card- and from that meeting other things followed and the word got around and we managed to do meetings in either one of the houses. There were quite a few people who had relatives affected like us, and we grew and grew. ${ }^{55}$

The first exploratory meeting was held on 25 July 1970 at the Wellcome Building on Euston Road.56 Pringle chaired the meeting, and it was decided that steps should be taken, primarily through advertising, to find out how many 'relatives of schizophrenics and others interested would be prepared to join a Schizophrenia Society, if formed. ${ }^{57}$ Interestingly, whilst the meeting unanimously decided that it wanted its membership to be 'as far reaching as possible,' from the very beginning, this was a society for relatives, rather than specifically for those suffering from schizophrenia themselves. ${ }^{58}$ It was stated that the 'prime objectives of a schizophrenia society would be to bring help and support to relatives of schizophrenics and to improve public provision, and to enhance knowledge. ${ }^{59}$ Indeed, one of their main original aims, in addition to lobbying the government for change, was to 'run a counselling service for relatives. ${ }^{60}$ It was even questioned in the first meeting whether membership of the society should be solely limited to close relatives and parents of schizophrenics. This suggestion was not taken up; it was decided instead in favour of allowing mental health specialists and others with a specialist interest to partake in membership. ${ }^{61}$ Nevertheless, despite the inclusion of specialists, it is clear that relatives were the primary membership and the real reason for the establishment of the society. 
The idea that the Fellowship was able to bring relatives and caregivers together was amongst its key success. Together, it was felt that they were able to look after each other and beat the stigma of schizophrenia. This was amongst the main aim of the society when it was first established. It was felt that 'since the feelings of loneliness by those coping with schizophrenia may sometimes be helped by meeting and talking to others who are, or who have been, in the same case, it might be possible to arrange local or area meetings. ${ }^{62}$ By October 1975, these local meetings were in successful operation. It was noted that these group meetings were spaces in which problems could be discussed, and members provided with advice, support and mutual companionship. ${ }^{63}$ In this way, during these meetings, the National Schizophrenia Fellowship allowed E.A. to open up and be able to talk to people in a safe and non-judgemental environment. Here, she was able to talk about her difficulties and about her brother, safe in the knowledge that here, her promise could remain unbroken.

When these meetings started up, you felt quite cheered up, you felt positive; it was something. You felt like you were doing something and that we would get there somehow and it was so nice to be able to open up to people instead of pussy-footing around all the time- I had got fed up with it and that was a very strong development eight years after P.A. was diagnosed in his condition. At last I had met other people in the same position and we didn't judge each other or anything so that is a very strong thing that Rethink do- getting people together. ${ }^{64}$

On 6 October 1975, the NSF could claim that it had over 1000 members, reaching nearly 1500 individuals. ${ }^{65}$ It was boasted that the Fellowship had members across the UK, in Northern Ireland and the Irish Republic. Talks were even being held to try to set up similar fellowships in New Zealand, Japan and South Africa. ${ }^{66}$ By the Annual General Meeting of February 1976, there were sixty local NSF groups established in local districts. ${ }^{67}$ The chairman stated his pride that already these groups' 'views and needs were been listened to and even sought after by staffs of the Health and Social Services. Individual members had found that they could offer each other help, advice and mutual companionship which they had often been without for many years. ${ }^{68}$ One member was quoted as having stated 'how marvellous' the NSF was, claiming 'I want to jump on my roof-top and shout out that I have schizophrenia in my 
family after twenty years of isolation.' ${ }^{69}$ However, it was clear that this was just the beginning and they already had plans to grow their number of sixty support groups. Future plans were not only to increase the number, but also to increase the scope of the work of these local groups. The Annual Report identified that 'the local groups were looking towards an intensification of self-help, befriending, sitting in, arranging holidays and so on... ${ }^{70}$ E.A. explains;

From then, we had a donation from somebody, I don't know if I should mention their name but they were very well respected in the science world and the banking world and they gave us about $£ 3000$ to set up an official [head-quarters] - she herself was affected by a relative and that money helped us to set up an office in Surbiton at the time. So little by little it has grown. We set up support groups in various areas and then we tried to make it nationwide. And they seem to me to have done a good job. ${ }^{71}$

Members received a variety of benefits for their $£ 2.50$ subscription money. They were entitled to receive a regular newsletter, pamphlets and leaflets setting out practical guidance for looking after relatives with the disease. Families were also entitled to membership at a local group meeting. The Member's Pamphlet explained that members would benefit from the 'sense of belonging to a national society run by relatives for relatives, whose sole purpose is to secure a better life for people with schizophrenia and their families. ${ }^{72}$ In this way, the Fellowship was ardently set up as an organisation not solely for the benefit of the schizophrenic, but as a release valve and coping mechanism for the healthy-minded relative being pushed into an unhealthy life of anxiety and isolation by the illness.

\section{BetTer Together}

Despite being positive of her own experiences of the medical professionals, E.A. was exceptionally critical about any attempt to undercut funding and reduce services available for mental health work. Her membership of the National Schizophrenia Fellowship allowed her access to Service Review Meetings, and she was critical here of the mindset of reducing services to cut costs in the mental health budget. ${ }^{73}$

I was asked to go along, not because I was a medical person, but because a social services for Hammersmith Mental Health Occupation Therapist asked me to go along, as her sidekick I suppose you might call it, because 
she said that I might be able to say things that she as an employee of the council might not be able to say. And I remember at one time I really was incensed because they said that various inspectors had been going around and they had seen nurses playing table tennis with a patient and they were regarding it as messing about- really(!)- They were not regarding this as therapy! So they were obviously thinking that nurses themselves were not on duty- they had not got the mind-set and I was worried. This was before the mental hospitals had closed, just as they were coming up for closure and I remember saying- to someone-they were trying to work out how they could have the minimum in the community- the minimum number of CPNs and when I questioned it they said “it's all very well, but there isn't the money in the NHS and we have got to keep in our budget and we just can't afford to have CPNs playing noughts and crosses ... we just cannot afford it." And I said to them... "if you want successful community care for people who are mentally ill, you cannot afford not to... They must be there!" There was a long silence. Nobody said anymore. The meeting went on. I was never asked again to the service review but the Occupational Therapist said to me, "I am so glad that you said that- I couldn't have said that... but you're independent." 74

In other respects, the National Schizophrenia Fellowship was an important body which lobbied the government to change the system. The Annual Reports document work carried out and early reports set the tone for encouraging change. The early publication, The Problem Before $U$ s, set out the Fellowship's claim for the deficiencies in caring for those with schizophrenia. The document listed a range of issues that needed addressing, such as inadequate spending on research, negative public attitudes and stigma towards the illness, ignorance of mental illness amongst general practitioners and a basic unfamiliarity with committal procedures amongst general practitioners, amongst many. ${ }^{75}$ In turn, the ideas behind this work came from the problems identified in Pringle's original letter, which was so powerful in terms of finding publicity in The Times. The early pressure group focused on trying to rectify some of the issues put forward in Pringle's original letter, which highlighted the need for a 'unified national policy' when it came to trying to deal with the problem of schizophrenia. Much time and effort was put into the charity's efforts to arrange 'small residential settlements' where the schizophrenic's basic needs could be provided for. In turn, the benefits being fought for would have had a huge impact on the families and caregivers of individuals with schizophrenia. These ideas culminated in a report of 
recommendations submitted to the Secretary of State, Barbara Castle, on the 'Social Provision for Sufferers from Chronic Schizophrenia." ${ }^{76}$

By the late 1970s, a host of different pamphlets and publications had been made available by the NSF. These were originally designed for members only; however, it soon became apparent that they could attract a 'good deal of publicity.' The brochure entitled Schizophrenia had been handed to the national press, and this had led to a huge demand from general practitioners and social workers. ${ }^{77}$ Further interviews in the national press led to publicity on the television, and information provided by the Fellowship was screened as part of a 'Horizon' documentary on BBC2 in March 1974. All of this publicity meant that the Fellowship was able to grow, both in terms of a pressure group, but also in their influence nationally as well as in individual families.

These pamphlets were designed very specifically to meet a perceived gap in the market for knowledge. Early in his endeavours to set up the Fellowship, Pringle wrote: 'The bewilderment and loneliness of relatives trying to make sense of the appalling thing that hits them is being helped very little, if at all. The BMA [British Medical Association] and the N.A.M.H. have leaflets for relatives of a primarily soothing and not very adequate kind. The society are starting hopes to do better than this. ${ }^{78}$ Talking about the impact that Rethink has on her modern day life, E.A. identifies that the explanation of medical information is now one of the things she values the most.

What I value about in their journal, Your Voice, is all the information about new medications coming on, because they do help. So I very much enjoy reading about scientific developments and they are very good at that- factsheets- and things like that... that is one of the things that I still value and think how they can help two of my local friends when I read these factsheets. So that has a high priority with me. ${ }^{79}$

Whilst the pressure that the NSF was able to put on the government was not insubstantial in the late 1970s and early 1980s, this work was intensified during this period by a collection of other mental health charitable groups. The rebranded N.A.M.H., which had changed its name to MIND following a successful campaign in 1972, still had a dominant position in lobbying the government for change. It is clear from the quote above, however, that the NSF played a special role in thinking specifically about schizophrenia. The factsheets and pamphlets that they 
produced may have had a valuable role in increasing publicity and certainly found interest in the media at the time. However, again, it is clear that this information was the most valued by the society's membership. The fact that Pringle wanted the leaflets to be more 'adequate' for relatives and caregivers than those available by the BMA and the N.A.M.H. is very telling.

\section{Conclusions}

It is clear that to begin with, the NSF was established to respond to the loneliness, isolation and stigma felt by relatives and caregivers of those suffering from schizophrenia in the 1970s in Britain. E.A.'s story, Pringle's letter and the correspondence that he received, published in Living with Schizophrenia: By the Relatives in 1974, all show a remarkably similar story of individuals doing their best but suffering in relative isolation. Some people felt abandoned by family, some by friends and others by the NHS and medical staff themselves. The NSF was designed to bring these relatives and caregivers together and provide them with a voice. The Fellowship provided literature and pamphlets, explaining the illness, lobbied the government to provide change and worked with the media to try to dispel the myths and stigma surrounding schizophrenia. However, despite this work, the Fellowship itself remained one of the most important things, giving families and caregivers a voice and offering the comforting familiarity of friends who have had similar experiences. Advice was both scientific - in terms of the factsheets-but also based on human experience.

This supportive message of self-help was interconnected with every ambition of the Fellowship, including its very name. The aims of the Fellowship were cyclical; improving the life of the family member and caregiver and offering them information, advice and support would improve the life of the schizophrenic person and thereby improve the lives of their caregivers. To finish with the eloquent words of E.A. 'So whatever happens, Rethink is there and I feel that they will plug the gap. I will never forget the first time that I walked away from that first meeting- the first big meeting with lots of people there- and I thought more sort of hopeful and more normal, instead of sort of cut off from people and so that.... can all help make a difference. ${ }^{80}$ E.A.'s words are suggestive; it would appear that becoming a member of the NSF could help 
to support relatives struggling with stigma and act as a barrier to this stigma, by providing help, mutual friendship and strategies of coping for the 'healthy mind' of the non-schizophrenic caregiver.

Acknowledgements I would like to thank Mark Winstanley (Chief Executive of Rethink Mental Illness) and the people at Rethink for allowing me to access the archives and providing funding to do so. My biggest thanks go to E.A., my interviewee, for allowing me to publish this material, and being so welcoming. Your zest and enthusiasm for life is infectious.

\section{Notes}

1. NSF Archive: Schizophrenia Action Committee, 'Schizophrenia: Could You Help?' (1970).

2. Ibid.

3. Ibid. Emphasis original.

4. Brea Perry, 50 Years After Deinstitutionalisation: Mental Illness in Contemporary Societies (London: Emerald Group Publishing Ltd, 2016); Helen Killaspy, "From the Asylum to Community Care: Learning from Experience," British Medical Bulletin 79, no. I (June 2006): 245-258; John Welshman, "Rhetoric and Reality: Community Care in England and Wales, 1948-74," in Outside the Walls of the Asylum: The History of Care in the Community 1750-2000, eds. Peter Bartlett and David Wright (London and New Brunswick: The Athlone Press, 1999); Peter Barham, Closing the Asylum: The Mental Patient in Modern Society (London: Penguin Books, 1992).

5. Dylan Tomlinson, "What Happened to the Patients?" in Utopia, Community Care and the Retreat from the Asylums (Milton Keynes and Philadelphia: Open University Press, 1991), 135-155.

6. Alex Mold, Making the Patient Consumer: Patient Organisations and Health Consumerism in Britain (Manchester: Manchester University Press, 2015), 18.

7. Ali Haggett, "Preventing Male Mental Illness in Post-war Britain," in Preventing Mental Illness: Past, Present and Future, eds. Despo Kritsotaki, Vicky Long, and Matthew Smith (Basingstoke: Palgrave Macmillan, 2019), 261.

8. John K. Walton, "Casting Out and Bringing Back in Victorian England, Pauper Lunatics, 1840-70," in The Anatomy of Madness: Essays in the History of Psychiatry, eds. W. F. Bynum, R. Porter, and M. Shepherd (London: Tavistock, 1985), 132-146.

9. David Wright, "Getting Out of the Asylum: Understanding the Confinement of the Insane in the Nineteenth Century," Social History 
of Medicine 10, no. 1 (April 1997): 137-155; David Wright, Mental Disability in Victorian England: The Earlswood Asylum, 1847-1901 (Oxford: Oxford University Press, 2001); Louise Wannell, "Patient's Relatives and Psychiatric Doctors: Letter Writing in the York Retreat, 1875-1910," Social History of Medicine 20, no. 2 (August 2007): 297313, 297.

10. Nicole Baur, "Family Influence and Psychiatric Care: Physical Treatments in Devon Mental Hospitals c. 1920 to the 1970s," Endeavour 37, no. 3 (July 2013): 172-183, 177.

11. Anon, "A Case of Schizophrenia by a Correspondent," The Times, 9 May 1970.

12. John Pringle, "Living with Schizophrenia," Mind and Mental Health Magazine (Spring 1972): 15.

13. Nick Crossley, "Transforming the Mental Health Field: the Early History of the National Health Association of Mental Health," Sociology of Health and Illness 20, no. 4 (December 2001): 458-488.

14. Vicky Long, Destigmatising Mental Illness? Professional Politics and Public Education in Britain, 1870-1970 (Manchester: Manchester University Press, 2014), 162.

15. NSF Archive, Personal Papers, 29 July 1970.

16. Ibid.

17. Nick Crossley, Contesting Psychiatry: Social Movements in Mental Health (London and New York: Routledge, 2006).

18. Barham, Closing the Asylum, 144.

19. For a discussion of stigma linked to mental illness, see: Long, Destigmatising Mental Illness?

20. A.B. Interview with E.A. recorded 11.04.2018. (Timing: 00.23:13-00:23:24).

21. E.A. accepted the use of the terms E.A. referring to herself and P.A. referring to her brother as acceptable for this publication.

22. Interview with E.A. $(00: 45: 30)$.

23. Interview with E.A. (00:44:09-00:44.45).

24. Interview with E.A. (00:49:14-00:49:24).

25. Interview with E.A. (00:51:10-00.53.20).

26. Interview with E.A. (00:56:20-00:56:30).

27. Interview with E.A. (00:56:40-00:57:11).

28. Interview with E.A. (01:03:37-01:04:47).

29. Interview with E.A. (01:19:26-01:20:03).

30. Interview with E.A. (00:22:32-00:22:54).

31. Interview with E.A. (00:15:16-00:17:33).

32. Interview with E.A. (00:24:28-00:24:40).

33. Interview with E.A. (01:20:04-01:20:58). 
34. Interview with E.A. (00:08:55-00:09:41).

35. Interview with E.A. (00:24:09-00:24:27).

36. Interview with E.A. (00:00:27-00:01:28).

37. John Pringle, "Living with Schizophrenia," Mind and Mental Health Magazine (Spring 1972), 15-20.

38. NSF Archive, The Problem Before Us. No date.

39. Ibid.

40. NSF Archive, Personal Correspondence, J. K. Wing to John Pringle, 3 October 1972.

41. See J. Wing and Clare Creer, Schizophrenia at Home (1974); Anon, Living with Schizophrenia-By the Relatives (1974).

42. Anon, "A Case of Schizophrenia by a Correspondent," The Times, 9 May 1970 .

43. Ibid.

44. Ibid.

45. Ibid.

46. Ibid.

47. NSF Archive, Correspondence-John Pringle to Rt Hon. Christopher Mayhew M.P., 20 July 1970.

48. Ibid.

49. Anon, Living with Schizophrenia.

50. NSF Archive, Correspondence-John Pringle to Rt Hon. Christopher Mayhew M.P., 20 July 1970.

51. Long, Destigmatising Mental Illness, 163.

52. NSF Archive, Personal Papers, 29 July 1970.

53. NSF Archive, Correspondence-John Pringle to Rt Hon. Mrs. Lane M.P., 22 July 1970.

54. Interview with E.A. (01:10:06-01:12:39).

55. Interview with E.A. (01:12:33-01:13:49).

56. NSF Archives: Memorandum and Articles of Association of the National Schizophrenia Fellowship (September 1975).

57. Ibid.

58. Ibid.

59. NSF Archive, The Problem Before Us.

60. Ibid.

61. Ibid.

62. Ibid.

63. NSF Archive, General Papers, 6 October 1975.

64. Interview with E.A. (01:21:36-01:22:42).

65. Membership could include a 'family membership,' whereby one subscription would allow both a husband and wife to access resources.

66. NSF Archive, General Papers, 6 October 1975. 
67. NSF Archive, Minutes of the Annual General Meeting (February 1976).

68. Ibid.

69. NSF Archive, General Papers, 6 October 1975.

70. NSF Archive, Minutes of the Annual General Meeting (February 1976).

71. Interview with E.A. (01:14:37-01:15:52).

72. NSF Archive, National Schizophrenia Fellowship, Member's Pamphlet, 1974. Emphasis original.

73. Interview with E.A. (00:57:30).

74. Interview with E.A. (00:58:00-01:01:49).

75. NSF Archive, The Problem Before Us. No date.

76. NSF Archive, 'Social Provision for Sufferers from Chronic Schizophrenia.' Recommendations, June 1974.

77. NSF Archive, Schizophrenia. No date.

78. NSF Archive, Personal Correspondence to John Day, 10 May 1971.

79. Interview with E.A. (01:17:50-01:18:08).

80. Interview with E.A. (01:22:54-01:23:56).

Open Access This chapter is licensed under the terms of the Creative Commons Attribution 4.0 International License (http://creativecommons.org/licenses/ by $/ 4.0 /$ ), which permits use, sharing, adaptation, distribution and reproduction in any medium or format, as long as you give appropriate credit to the original author(s) and the source, provide a link to the Creative Commons license and indicate if changes were made.

The images or other third party material in this chapter are included in the chapter's Creative Commons license, unless indicated otherwise in a credit line to the material. If material is not included in the chapter's Creative Commons license and your intended use is not permitted by statutory regulation or exceeds the permitted use, you will need to obtain permission directly from the copyright holder.

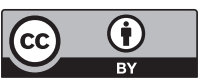

